
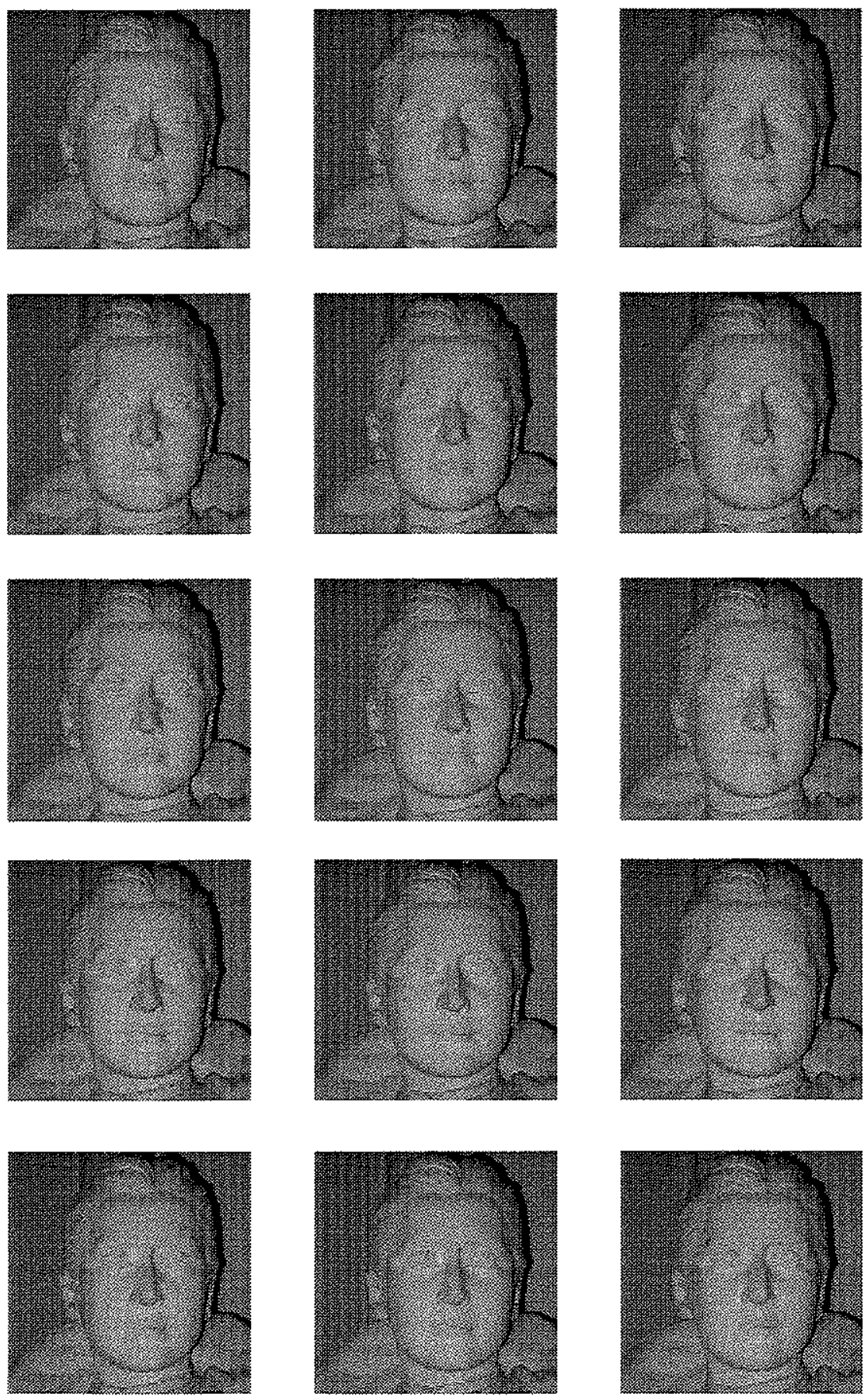


\title{
UNA APROXIMACIÓN ANTROPOLÓGICA AL DISEÑO CONTEMPORÁNEO
}

\author{
Hugo Valdivia Carlsson \\ Universidad Tecnológica Metropolitana \\ Universidad de Chile
}

LA ANALITICA DE LA EXISTENCIA HUMANA DE JOSÉ ORTEGA Y GASSET, $Y$ EL DISCURSO DE LA RAZÓN PROYECTUAL DE TOMÁS MALDONADO PERMITEN PONER EN EVIDENCIA LA RELACIÓN DEL DISEÑO CON LOS PRECEPTOS DE LA MODERNIDAD.

Lo que sea "diseño" se nos muestra como un tipo particular de acto inscrito en la vida humana, contexto donde se expresa su sentido, su importancia y su relevancia respecto de otros actos humanos.

Ortega y Gasset nos señala que toda praxis deriva de los proyectos de existencia que los individuos o colectivos se plantean. El proyecto o programa de existencia que los hombres se proponen realizar, crea sobre el mundo un conjunto de significados, las que resultan favorables o desfavorables al programa vital.

Las dificultades que las circunstancias presentan, con relación al proyecto de hombre que se ha asumido, generan una estructura de necesidades que son diferentes para cada comunidad. Ante la red de necesidades emergentes y como una forma de liberarse de la enajenación que ellas imponen, el hombre reacciona mediante actos cuya finalidad es transformar la circunstancia para anular las necesidades y hacerla adecuada a la consecución del proyecto vital.

Frente a lo que se reconoce como una necesidad el hombre ejecuta un tipo de actividad intencional que se expresa en "actos" transformadores de las circunstancias 
y cuya función es modificar el entorno para anular las necesidades. Existen muchos tipos de actos humanos, sin embargo si ellos se expresan en útiles o complejo de útiles estamos ante la presencia de "actos técnicos". Ortega define los actos técnicos como aquellos en que dedicamos el esfuerzo, primero a inventar y luego a ejecutar un plan de actividad que permite: 1 .- Asegurar la satisfacción de las necesidades, 2.- Lograr esa satisfacción con el mínimo esfuerzo y 3.- Crear posibilidades nuevas.

Por lo tanto, extrapolando los conceptos anteriores, podemos señalar que al decir la palabra "diseño" hacemos referencia al menos a tres entidades: r.- Una forma de acto humano vinculado a la categoría de actos técnicos (productores de útiles), 2.- Los resultados de aquellos actos (los objetos u obras de diseño), 3.- Una disciplina profesional que, de modo progresivo, tiende a unificar y cohesionar mediante el discurso, aquellos actos y sus productos (el discurso proyectual).

El conjunto de aquellos referentes encuentra su explicación en el proyecto humano que le dio origen y que en occidente, con evidentes diferencias locales, se

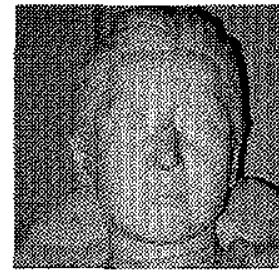
adscribe al discurso del proyecto moderno. Se trata de un paradigma de base cultural que sostiene a la razón como modo de penetración del mundo y una idea de progreso que se sostiene sobre el aparato productivo de la sociedad y que, en occidente, corresponde a la industria moderna.

Sin embargo, todo proyecto se desenvuelve entre dos polos: r.- El estado actual de desarrollo y 2.- El estado ideal o aspirado. Por lo tanto, desde sus orígenes la modernidad ha significado cambios progresivos y teleológicamente orientados en casi todos los aspectos de la vida. Resultan relevantes los siguientes: $\mathrm{r}$.- Desarrollo del conocimiento críticamente fundado, 2.- Constitución progresiva de una sociedad secular con fundamento en una nueva axiología, 3.- Orientación al futuro y al progreso, 4.Modificaciones radicales del lenguaje, con importantes aportes de las ciencias y las tecnologías, 5.- Constitución del capitalismo y su antítesis, 6.- Transformación global de las estructuras sociales.

En consecuencia la historia del diseño, así como la de otras disciplinas proyectuales, debe entenderse, dentro del contexto anterior, como el conjunto de sus acontecimientos disciplinarios y profesionales que se 
orientan a un estado cultural final, ideal y en cierta medida utópico, que corresponde al proyecto de existencia que occidente se ha planteado para sí durante los últimos siglos: La modernidad.

Para Tomás Maldonado la relación entre proyecto y modernidad tiene dos aspectos claramente definidos: $\mathrm{I}$.- La modernidad es la resultante de la inteligencia proyectual y 2.- La actividad proyectual es el núcleo fundante de la modernidad. Ambos aspectos forman el discurso de la "razón proyectual".

Maldonado construye el discurso de la "razón proyectual" a partir de la pregunta acerca de las fuerzas que logran conformar la cultura material de la civilización occidental moderna, caracterizada por una plétora de artefactos, tanto materiales como comunicacionales, que se encuentran sometidos a un exponencial ritmo de innovación.

Maldonado sostiene que el proyecto moderno se realiza mediante la industria, $y$ es en ese contexto donde se advierte el rol y la importancia del diseño en la sociedad contemporánea. El diseño corresponde a una de las entidades que conforman las fuerzas productivas de nuestra cultura y que, junto a otras disciplinas proyectuales, han logrado crear un particular escenario que condiciona y permite que se desenvuelva la vida cotidiana de nuestra sociedad.

En síntesis, la modernidad se desenvuelve particularmente en la industria moderna; sin embargo, la industria es lo que es porque el futuro deseado determina hacia atrás el perfil de los actos proyectuales presentes.

Finalmente es necesario señalar que desde la década del 60 se ha verificado una corriente neoconservadora que, fundamentada en la pérdida de las creencias en las metanarrativas, sostiene el ocaso de la modernidad. La denominada postura posmodernista es especialmente grave para los países que aspiran al desarrollo porque es incongruente pretender ser postmoderno si aún no se ha logrado ser plenamente moderno, y porque renunciar al futuro significa renunciar al desarrollo. Es indispensable preguntarse acerca de cómo incide el proyecto de la modernidad en aquellas naciones que viven al margen de los polos económicos, políticos, científicos, tecnológicos y culturales.
UN TIPO DE

ACTIVIDAD

INTENCIONAL

QUE SE

EXPRESA

EN "ACTOS" TRANSFORMADORES 